\title{
Clare Gerada: Understanding burnout
}

\author{
Clare Gerada GP partner
}

Hurley Group, London

In my early 40s I felt exhausted: I was juggling general practice, motherhood, and carving a career in addiction. More than this, I'd lost my joy and zest for work. It had become routine-and, if I'm honest, caring for patients had become a burden. Until then I'd been an idealistic, enthusiastic, engaged GP and had truly loved my work, especially the patient facing aspects. But now, medicine had lost its spark.

Looking back, I had classic burnout. Burnout is formally defined as a state of physical, emotional, and mental exhaustion caused by long term involvement in demanding situations. For me it conjures up an image of "destroyed" individuals, shells of their former selves, damaged by the "fire" of their work that rages around them.

Today, burnout is the single most prevalent psychological complaint in the caring profession. So prevalent is it that, at some point in our career, anyone working close to human suffering will develop some aspects of it.

Although the intensity, duration, and consequences of burnout may vary among individuals and across time in the same person, it's always a combination of those components: physical, emotional, and mental exhaustion. After I ran the London marathon in 2004, I was exhausted but elated. That was clearly not burnout.

Burnout is thought to be distinct from depression, but I prefer to think of them as part of the same process. There's a considerable overlap between symptoms (particularly around hopelessness, poor self-esteem, and sleep disturbance), and it may be deemed more acceptable to call oneself "burnt out" than "depressed." But the two are clearly linked. A study from Finland found a relation between burnout and depression, with each predicting subsequent developments in the other. ${ }^{1}$ High levels of burnout have been linked to a high level of antidepressant medication. ${ }^{2}$

The covid-19 crisis is putting additional pressure on doctors and the health system in general. An Ipsos MORI poll has reported that half of workers already believe that their mental health has declined in the first two months of the crisis, ${ }^{3}$ and if covid-19 has even the same psychological impact as other major pandemics a vast number of key workers will need support. ${ }^{4}$ The strain on the medical profession is already being felt. A BMA survey conducted from 14 to 16 April found that almost half of UK doctors were experiencing burnout, depression, anxiety, or other mental health conditions relating to their work or made worse by it. ${ }^{5}$

It's hard to prevent burnout—but we have to manage it, recognise it, minimise it, and deal with it when it occurs. We all have ebbs and flows in job satisfaction, and years of being in the psychological trenches with our patients will have an effect. What's important is recognising when we can't go on; when negative attitudes turn to loss of compassion; when our sense of futility becomes a feeling of hopelessness and helplessness; when our work loses its sparkle, day in, day out, and we need to remove ourselves from the stressor.

I was lucky: I worked for a practice that allowed me to take a sabbatical. Refreshed and reinvigorated, I returned and amended my working practice, which sustained me for the next two decades. The best place to start to reduce levels of burnout is in the workplace.

Competing interests: See www.bmj.com/about-bmj/freelance-contributors.

Provenance and peer review: Commissioned; not externally peer reviewed.

1 Ahola K, Hakanen J. Job strain, burnout, and depressive symptoms: a prospective study among dentists. J Affect Disord 2007:104:103-10. 10.1016/j.jad.2007.03.004 17448543 Leiter MP, Hakanen J, Toppinen-Tanner S, etal . Changes in burnout: a 12-year cohort study on organizational predictors and health outcomes. J Organ Behav 2013;34:959-7310.1002/job.1830.

3 Ipsos MORI; King's College, London. Life under lockdown: coronavirus in the UK. Apr 2020. https://www.kcl.ac.uk/policy-institute/assets/coronavirus-in-the-uk.pdf.

4 Maunder R. The experience of the 2003 SARS outbreak as a traumatic stress among frontline healthcare workers in Toronto: lessons learned. Royal Society. 2004. https:// www.ncbi.nlm.nih.gov/pmc/articles/PMC1693388/pdf/15306398.pdf.

5 BMA. Stress and burnout warning over COVID-19. 19 Apr 2020. https://www.bma.org.uk/ news-and-opinion/stress-and-burnout-warning-over-covid-19.

Published by the BMJ Publishing Group Limited. For permission to use (where not already granted under a licence) please go to http://group.bmj.com/group/rights-licensing/ permissions 